\title{
A RETURN ON INVESTMENT IN EMPLOYEE ASSISTANCE PROGRAMMES: A THEORETICAL UNDERPINNING
}

\section{Anneline Keet, Lourie Terblanche}

\section{INTRODUCTION}

Mental health conditions such as stress, depression, substance abuse and relational problems are major contributors to sickness, absenteeism and lower job performance (Nissly \& Mennen, 2002). Steward, Ricci, Chee, Hahn and Morganstein (2003) indicate that employees with depressive disorders present with almost four times more healthrelated lost productivity than those without depressive symptoms. This amounts to 5.6 hours per week lost by employees with depressive disorders in comparison with 1.5 hours lost by employees who do not suffer from these disorders, costing the United States economy up to $\$ 44$ billion per year. Steele (2002) maintains that workdays lost because of substance abuse alone cost the US economy \$5 billion dollars a year. In South Africa the Bytes Technology Group conducted a study (Bytes, 2011) indicating that local companies lose between R12 to R20 billion a year to absenteeism. An article in Rapport Loopbane (2 July 2006) also indicated that the cost of absenteeism for the South African economy was estimated at R20 billion for that year. It is unlikely that statistics have changed significantly over the last five years and the country continues to lose revenue through employee absenteeism.

\section{EMPLOYEE ASSISTANCE PROGRAMMES AND THEIR IMPACT ON PRODUCTIVITY}

Absenteeism has many underlying causes and the health condition of the country's working population may be one of these. Employee Assistance Programmes (EAPs) are employer-sponsored programmes designed to alleviate a range of workplace problems using core technologies such as screening, assessment, brief intervention and referral to service providers, case management and follow-up services for mental health and substance-abuse problems (Jacobson \& Attridge in Sweet \& Casey, 2010).

These programmes operate at the individual employee level using aspects of behavioural science for the assessment and management of certain work-related and non-workrelated problems. EAPs facilitate the assessment of an individual's progress from the time they show problematic personal and work-related behaviour to when they have achieved full functioning in both these areas. Selvik, Stephenson, Plaza and Sugden (2004) conducted a study of the EAP at the US Department of Health and Human Services and recorded a pre- and post-test difference between specific performance measures. Productivity affected by emotional challenges improved by $73 \%$, productivity affected by health problems improved by $66 \%$, relationship challenges improved by $74 \%$, and absenteeism and tardiness problems improved by $62 \%$. It is thus possible to assume that behavioural science interventions on the individual employee level may have positive spinoffs for workplace performance. Attridge, Amaral, Bjornson, Goplerud, Herlihy and McPherson (2010) present an EAP business value model 
consisting of three categories by means of which the programme's worth can be evaluated and expressed. These categories are like building blocks, with one component building on the other. The figure below illustrates this model.

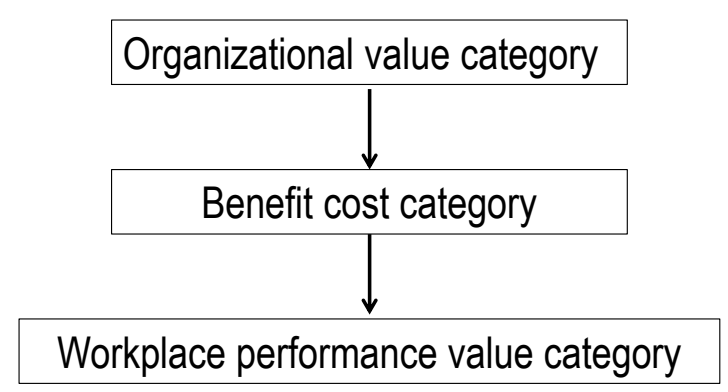

Attridge et al. (2010): EAP Business Value Model

The workplace performance value category refers to the positive changes in employee performance as a result of the EAP. The benefit-cost category refers to the effect of the EAP on the employer-paid medical benefits used in areas of medical and pharmaceutical, mental health, disability and workers' compensation, regarded as direct costs to the employer. The organisational value category refers to savings owing to effective safety risk management, legal liability management and a positive improvement in organisational culture. This study focuses primarily on the workplace performance value category.

\section{THE NEED TO PROVE VALUE THROUGH PROGRAMME EVALUATION}

In an online article (December 2011) the Chicagoland Chamber of Commerce indicates that, according to a Business Insurance survey, EAPs in the US grew by $318 \%$ after 2002. Whereas in 200237.4 million lives had been covered, by 2011 the figure had grown to 156.9 million (http://www.chicagolandchambers.org). These statistics may actually be pointing to the real growth, representing as they do the growth of the top ten EAPs in the US. This does not include the growth associated with the smaller EAPs. There has been a significant increase in company investment in employee wellbeing resulting from the EAP. Attridge (2010) indicates that over the last 30 years a number of studies had shown positive outcomes for EAPs in different areas, especially in the workplace performance and benefit-cost categories. Masi (1994) cited some of these studies in an article and refers to the Kennecott Copper Corporation, which estimated a 6:1 benefit-cost ratio resulting from employees' use of its EAP. Equitable Life Assurance found a $\$ 3$ return for every $\$ 1$ invested in its EAPs, when alcoholic employee absenteeism dropped from $8 \%$ to $4 \%$ after referral to, and treatment in, alcohol programmes. 3M Company data suggested that $80 \%$ of the employees who used the EAP showed improved attendance, greater productivity, and enhanced family and community relations. The McDonnell Douglas study, often quoted as an example of a cost-effectiveness study, determined that the EAP treatment of alcoholism was more effective than others. Csiernik (2004) reflected on studies conducted during the 1990s showing different forms of benefit. In 1994 Bruhnsen, a unit in the Michigan Medical Centre, found that EAP clients had a higher employee retention rate but no difference in 
sick days from non-EAP users. They still recorded a cost savings of $\$ 65.341$, reflecting significance in cost implications when positive change takes place in singular performance indicators. In 1998 the Chevron Corporation in the US found a significant return of $14: 1$ on an investment, while fewer substance-abusing employees were dismissed and both supervisor-referred (mean 50\%) and self-referred (mean 5\%) clients were observed. Safety rates remained identical. A study (1996) of the Southern California Edison EAP showed that users had higher initial addiction treatment costs, but subsequently lower mental and physical health care costs. EAP users had 38\% fewer medical costs over a 30-month post-treatment period. In 1999 the United States Postal Services reflected a benefit to cost ratio of 1.27:1 for the first year after EAP use. By the fifth year, the ratio was 7.21:1. Cost savings thus increased progressively after EAP use.

Despite evidence generated in such studies, Attridge (2010) maintains that the EAP industry persists in its perception that there is insufficient proof of its value. Seidi (2010) indicates that the necessity of evaluating EAPs is increasing, with purchasers insisting that providers prove the value of their product. Employee Assistance providers are thus under increasing pressure to ensure that their programmes have sound evaluation components able to measure the impact of their services. Seidi regards the development of specific metrics to measure the effectiveness of workplace counselling as being much more than just a sales pitch. He sees this meticulous business-focused analysis as the primary means by which the industry can demonstrate that an EAP is a professional, systematically-applied intervention that generates a return beyond its cost. The development of these analytical capabilities will save the industry from what he refers to as commoditisation. Seidi (2010) raised a concern about two forms of commoditisation. The first refers to the risk of being treated as a commodity, assessed according to its price rather than the value it adds to the organizational bottom-line. The second refers to EAPs keeping programme costs down, with low utilisation figures that undermine their real impact. These forms of commoditisation are driven by both the purchaser of an EAP and its supplier, which works against the true value of the industry. The trading characteristics of the industry are important only up to the point where it generates sustainable revenue. The researchers concur with Seidi's view that what distinguishes this intervention strategy from others is the particular behavioural science knowledge that the EA specialists bring to the workplace. The development and refinement of its analytical capabilities is what will promote the development and refinement of the industry as a discipline in its own right. Evaluation studies are one such strategy. Like Seidi, Csiernik (2004) argued that an EAP should have in place a mechanism whereby the appropriateness, effectiveness and efficiency of service delivery could be evaluated. This study demonstrates that measurement is possible, but could nevertheless be greatly enhanced if the ability to evaluate were built into programme design. Sharar and Lennox (2009) maintain that measuring tools for detecting change over time and directly connected with the expected, agreed outcomes should be built into programme design. These tools should coordinate scientific methodology with EAP practice by focusing on personal issues that directly affect workplace productivity. They should be automated to 
simplify and expedite survey methods for employees and all parties interested in the outcomes.

\section{METHODOLOGY USED IN THIS STUDY}

The researcher conducted a summative evaluation of two EAPs. Return on investment studies generally falls into the category of summative evaluation. Company $\mathrm{A}$ is a motor-vehicle production company and Company B a major financial institution. Both companies were using the same EAP service provider at the time of the evaluation. The EAP at Company A has been operating since 1995, that at Company B since 2000. Company A employs a significant number of blue-collar workers, while company B employs a significantly higher number of white-collar workers. The researcher used a quantitative research strategy with a smaller qualitative component and used data triangulation in order to explore the value of both quantitative and qualitative data in programme evaluation (De Vos, Strydom, Fouché \& Delport, 2011). The study focuses on EAP cases of employees who were referred to the programme via only the formal referral process, meaning that their line managers referred them because of identified performance challenges. Systematic sampling was followed, with the selection of every second person referred through the formal referral process for the demarcated period. The sample was comprised of 29 employees from Company A and 12 from Company B, all of whom were available during this specific referral period. Company B made less use of the formal referral procedure and five of the employees identified were not available for participation at the time. Twenty-four (24) line managers, 12 from each company, who were responsible for the referral of the employees, participated in the qualitative component of the study, engaging in semi-structured interviews. The human resource data for 20 of the respondents from Company A were available for the statistical data-analysis component of the study. Unfortunately, this step had to be omitted for the respondents from Company B, because of their low margin of permission. All the respondents and participants in the study gave their consent. Consent for access to HR data was obtained in addition to their initial participation in the programme. On-site counsellors at Company A and line managers from both companies played a supportive role in the distribution and completion of the questionnaires Respondents (employees) were consequently able to interact with people they knew well, rather than feeling exposed to a researcher with whom they were relatively unfamiliar.

A survey was conducted by means of questionnaires completed by the employee sample, which formed the quantitative part of the study. The survey focused on the following personal and performance indicators: personal-relational impact, work performance before and after participation, attendance, presenteeism, consideration of leaving the job, counselling and disciplinary action. The statistical data analysis focused on absenteeism and disciplinary action one year before programme participation and one year subsequent to that. The semi-structured interviews conducted with referral agents (line managers) as a qualitative data collection instrument focused on the support given to line managers for using the programme effectively. This covered their understanding of the referral process, their perception of the impact of employees' personal problems on 
productivity, the financial implications of productivity problems, the impact of employees' personal problems on teams, their perception of the programme's ability to effect change and their views on the consistency of this change.

\section{RESULTS}

The goal of the research was to evaluate EAPs in the South African context by exploring the return on investment in the programme by two corporate clients of a specific EAP service provider in the region. There was a specific focus on the counselling component of the programme involving the targeted employees using the programme via the formal referral process.

The objectives of the study were:

- To investigate the impact of the EAP on organisations focusing on performance indicators such as absenteeism, on-the-job absenteeism, productivity and disciplinary action;

- Using different data-collection tools, to provide guidelines for programme evaluation including ROI tools for determining the value of EAPs as well as identifying growth areas;

- To investigate the consistency of data from different measuring instruments: selfreporting, qualitative impressions from referral agents and statistical data analysis.

De Vos et al. (2011) warn that the results of all cost-benefit analyses should be considered carefully, as its value is time-bound and influenced by the estimates and assumptions on which it is based. This description of how these results should be viewed could to some extent provide an answer to the concern in Attridge (2010) that, despite so many completed studies reflecting a positive return on investment, the value of the programme remains in question. At the same time, De Vos et al. (2011) maintain that these evaluation studies are necessary, as they create a foundation for policy decisions. They could therefore influence the direction of EAP programme operations.

As far as this study is concerned, the authors consider that the results should be seen both for their possible ROI value, and because there are lessons to be learned about the important elements needed for programme evaluation studies. Aspects for consideration in this respect are recognition of the uniqueness of data sources and exploration of the value of the data they generate. The researchers strongly concur with Seidi's views on the need to build the discipline rather than commoditise the industry through consistent evaluation studies.

The data obtained in this study reflect a measure of change from one level of functioning to another. Change in relationships (personal and work-related) in following both the quantitative and qualitative approaches and change in identified performance indicators has been reported.

The following data set reflects the results from the self-reported questionnaires, a subsection of the quantitative component of the research. 
FIGURE 1

NEGATIVE IMPACT OF PERSONAL PROBLEMS ON WORK PERFORMANCE

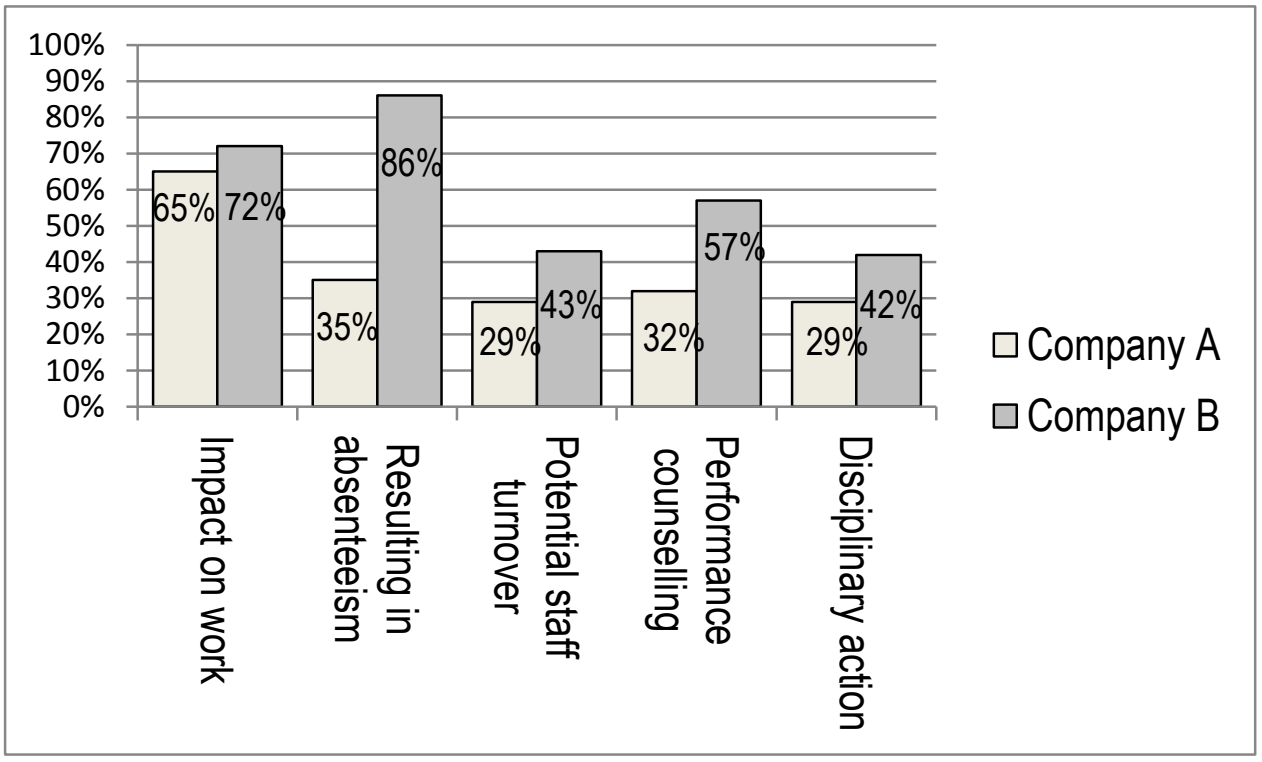

FIGURE 2

REPORTED IMPROVEMENT AFTER EAP ATTENDANCE

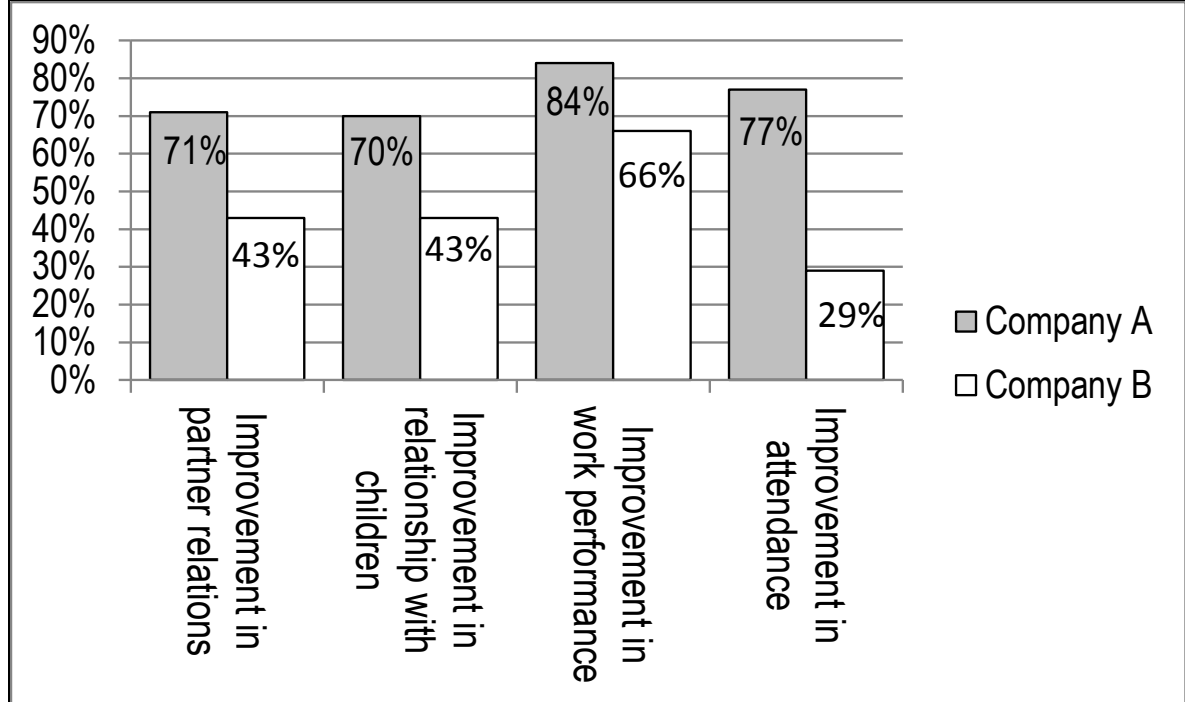

The self-reporting quantitative results show that personal problems had a negative impact on employee attendance, resulted in disciplinary and staff counselling processes for many of the respondents, and impacted significantly on employee work performance. The majority of respondents from both companies said their work performance was negatively affected by their personal problems. Opinions differed as to whether their performance necessarily included absenteeism patterns. Company A reported a less significant impact on attendance than did Company B. Respondents from Company B were generally of the opinion that their personal problems did not have an adverse effect on their relationships with their partners. However, they did report a general improvement in personal relationships after participating in the programme. One of the weaknesses of a study of this nature, one that uses employees who participated in the 
programme as an essential population, is that those who had left the company could not be included in the measurement. The self-reporting nature of this information is strengthened by the general consistency of viewpoints among respondents from the same company, qualitative feedback from line managers and data generated by the two different companies.

The statistical data for Company A show significant absenteeism before the EAP and a considerable decrease in the period following participation. The return on investment for this indicator was a saving of R14.60 for each R1 spent. One participant showed an increase in absenteeism, and another showed the same number of days absent. Nevertheless, from the previous 291 days for the 12 -month period before the EAP was held, down to 116 days for the 12 months following the programme, there was an overall decrease of 174 days. During the 12-month period before participation in the EAP 14 of the 20 employees whose human resource data were available for analysis had disciplinary action taken against them. In the period following the EAP, this number was reduced to five. The ROI on this indicator showed a saving of R8.30 for each R1 spent. The absence of corresponding data from Company B strengthens the argument that data management significantly influences or even determines the feasibility of programme evaluation. If an organisation maintains its $\mathrm{HR}$ data on employee performance indicators, statistical data analysis can serve as a stable data source for ROI purposes.

The overall ROI calculation for the programme included the total annual amount paid by each company for their EAP, international benchmarks for productivity loss owing to troubled employees, the average income and the total number of employees using the programme during a specific period. The companies' overall reported improvement in performance for all programme users is also reflected in the data below. The ROI calculation below thus includes both the respondents in the study and the total number of employees who used the service during the period. Thus there are specifics for the participants and the overall performance of the programme.

Company A spends R1 m annually on their entire EAP programme.

- The company's success indicators for EAP participation indicated a 78\% success rate.

- $65 \%$ of the respondents in this research who used the programme over that period indicated that their performance was affected by their personal problems.

- The average income is R6 000 per month, which amounts to R72 000 annually.

- International benchmarks indicate that organisations lose $28-35 \%$ of a troubled employee's income to lower productivity.

- R72 000 divided by 28\% = R20 160 (lower limit loss)

- R72 000 divided by 35\% = R25 200 (higher limit loss).

- Savings to company.

- R20 160 x $1060=$ R21 $379140 @ 28 \%$ productivity loss

- R25 $200 \times 1060=$ R26 $172000 @ 35 \%$ productivity loss 
- ROI @ 28\% productivity loss = R2.03 for every R1 spent

- ROI @ 35\% productivity loss = R2.51 for every R1 spent.

Company B spend R2 970000 annually on their entire EAP programme.

- The company success indicators for EAP participation showed a 78\% success rate.

- $72 \%$ of the respondents in this research who used the programme over that period indicated that their performance was affected by their personal problems.

- The average income R10 053.00 per month = R120 636 annually.

- International benchmarks indicate that organisations lose $28-35 \%$ of a troubled employee's income to lower productivity.

- R120 636 divided by 28\% = R33 778 (lower limit loss)

- R120 636 divided by 35\% = R 42222.60 (higher limit loss).

- Savings to company at $72 \%$ success rate:

- R33 778 x $1687=$ R56 $983486 @ 28 \%$ productivity loss

- R42 222.60 x $1687=$ R71 $229526.20 @ 35 \%$ productivity loss.

- ROI @ 28\% productivity loss = R1.81 for every R1 spent

- ROI @ 35\% productivity loss=R2.30 for every R1 spent.

The qualitative component was included in this study to obtain a more descriptive understanding of the impact of performance challenges over and above the numerical calculations. The participants selected for the qualitative component of the study were the line managers/supervisors responsible for referring the respondents to the EAP. As a result, their views on changes in attitude and work performance added objectivity to the views presented in the self-reporting component. The qualitative results show consistency across the two companies in the line managers' assessment of the impact of employees' personal problems on work performance, team work and supervisory roles. They also highlighted the financial and reputational risk factors that may be the result of challenges to employee work performance. The line managers who participated in this study held generally positive views on the impact of the programme, and unsuccessful cases were regarded as individual instances of non-positive responses rather than as programme failures. The line managers also expressed the need for training that would empower them to use the programme more effectively, with a more comprehensive understanding of mental health issues. The quotations below reflect some of these views.

\section{THE NEED FOR MORE COMPREHENSIVE AND CONSISTENT TRAINING FOR LINE MANAGERS}

Company A: Participant 1: "We have been to a couple of in-house training on how to check for guys for attendance, look at absence on Mondays/Fridays, coming under the influence, signs to look out for." 
Company B: Participant 2: "In my opinion there is a need to equip first line managers today with some of the most recent issues and developments and social issues people are bringing to work with them."

A question posed at a formal presentation of this report on 23 April $2009^{1}$ opened the debate on alternative forms of management training that would enhance their participation. This view also considers the possibility that failure to attend training sessions plays a role as great as if the training were not offered at all.

\section{THE IMPACT OF EMPLOYEES' PERSONAL PROBLEMS ON THEIR WORK PERFORMANCE}

Participants from both companies were of the opinion that employees' personal problems have a significant impact on their performance at work. In a productionorientated industry such as Company B, the direct impact is on the delivery of finished products.

Company A. Participant 2: "The person present with excessive absenteeism, lack of concentration on the job, withdrawn to themselves. If you give them an instruction they are unwilling to carry it out. The person may come late and leave the line early. You can see if they have been drinking the night before."

Company B. Participant 6: "The quality of the work deteriorates. We operate in a letter-writing environment to clients and regulatory bodies. You can pick up a lack of focus through a superficial response and bad grammar."

\section{FINANCIAL IMPLICATIONS OF LOWER PERFORMANCE}

Participant opinion was consistent across both companies on the financial and reputational risks of lower employee performance. This is a clear indication that employee wellbeing ought to be a strategic rather than a soft service discussion in organisations.

Company A. Participant 7: "If I have to build 100 cars I have to and not 95. Loss of production means loss of customers, up to 5 customers per day. Cars are made per order and not to store. It is detrimental to sales and we are thus not meeting market demand. We do have an annual market share and if I do not meet daily targets, the company cannot meet market sale. One customer means they speak to others, thus a loss of future customers. One vehicle cost about R200 000 and you thus struggle to make a profit."

Company B. Participant 5: "We accept risk on behalf of the company as we underwrite policies for people. Mistakes can put the company at risk of millions of rands... It is important for people to have good focus, feel confident about the decisions they make and know that they have followed all the steps and feel comfortable about these steps."

${ }^{1}$ Doctoral students enrolled in the Department of Social Work and Criminology at the University of Pretoria are required to present a seminar on the findings of their study. Dr Keet presented her doctoral seminar on 23 April 2009. 


\section{IMPACT OF TROUBLED EMPLOYEES ON TEAMS}

The participants from both companies maintained very similar views on the impact of troubled employees on their teams. Team cohesion can be adversely affected and the ability of management to intervene is generally scrutinised under these circumstances.

Company A. Participant 10: "It impacts a lot and there end up being no team work. We get complaints from the team and the person tends to fight with everybody."

Company B. Participant 2: "At a team level there is a lack of sympathy for the person, a lack of understanding. So it affects team dynamics."

\section{ABILITY OF PROGRAMME TO EFFECT CHANGE}

Participants generally had a positive view of the impact of the programme and were consistent in thinking that when employees were unable to make or sustain positive change, this was owing to personal dynamics rather than to failure of the programme. As a result, the way in which the intervention is offered is seen as sufficient.

Company A. Participant 5: "I definitely see an impact, example, one person was on the verge of termination due to alcoholism, I referred him... he is now a new man."

Company B. Participant 8: "Change happened much quicker than what I thought. I was surprised. The employee soon realised what she had to do and became more empowered."

\section{PERCEPTIONS ON CONSISTENCY OF CHANGE AFTER EAP PARTICIPATION}

Participants from both companies held strong and positive opinions on the changes taking place for troubled employees after their participation in the programme. This is consistent with the notion that solution-focused therapy, the model used in their respective programmes and in EAPs in general, is dynamic in nature with highly focused interviews helping clients develop insight into their problems, effecting long-lasting change in a time-efficient way (Stalikas \& De Stefano, 1997:2).

Company A. Participant 8: "People are more empowered but it is also a matter of choice. Most of the people who changed through the programme were able to sustain that change."

Company B. Participant 5: "Going forward the client was still faced with major challenges and if she did not receive help at that point she would have a major breakdown."

The information generated from the three different data sources used in this study supports the notion that EAPs add value to the profiles of organisations' human resources. The results of this study correspond with the literature used in this article, which points out that troubled employees have a negative effect on their company's financial bottom line. A behavioural science intervention such as an EAP is able to positively affect employees' wellbeing, as a result impacting on their behaviour both in the workplace and outside. 


\section{CONCLUDING REMARKS}

With the number of EAP evaluations and, more specifically, ROI studies that have already been conducted, it may be necessary to look at the refinement of the programme's analytical capabilities. Attridge et al. (2010) have already moved in this direction by categorising the different business value models. Attridge (2010) also argues that the use of the workplace performance category, or what he also terms the productivity path, allows evaluators to use validated self-report tools to measure employee work performance outcomes. These projects can be conducted at lower costs and within shorter time frames. There is also an alignment with one of the core targets of workplace behavioural health services, which is a change in work performance outcome. Sharar and Lennox (2009) discuss the need for measuring tools to be built into programme design to detect change over time. The software development capabilities available to EAP providers already allow them to design their tools to be user-friendly, to assess pre- and post-intervention behavioural indicators, identify all agreed-upon performance indicators and translate these into monetary values for the organisation. These measures can be complemented by qualitative strategies that create a deeper understanding of phenomena and provide answers for the industry and the discipline as to those actions that yield the most value to individuals and their organisations.

Human resource data are very useful to ROI studies in providing objective information for analytic purposes. Despite the EAP's stable and objective qualities, it is greatly influenced by the maintenance of credible systems and ethical access to them.

Qualitative interviews and conversations may not be a traditional part of ROI evaluation. However, if we are to understand phenomena beyond their monetary value, we must comprehend them from the perspective of those people who experience and understand them in their daily experience. Qualitative data also give direction for further quantitative research and can thus form a foundation for what Seidi (2010) refers to as the refinement of analytical capabilities that position the EAP as a discipline using professional, systematically applied interventions.

\section{REFERENCES}

ATTRIDGE, M. 2010. 20 Years of EAP cost research: taking the productivity path to ROI: this promising strategy can be accomplished with far fewer operational costs than traditional claims-based ROI studies and in far less time. The Journal of Employee Assistance, 40(4):8-11.

ATTRIDGE, M., AMARAL, T., BJORNSON, T., GOPLERUD, E., HERLIHY, P. \& McPHERSON, T. 2010. The business value of EAP: a conceptual model. EASNA Research Notes, 1(10):1-5.

CHICAGOLAND CHAMBER OF COMMERCE BUSINESS INSURANCE SURVEY. 2011. Growth of Employee Assistance Programs. December 2011. [Online] Available: http://www.chicagoland chambers.org/wdk_cc/innovation_and_knowledge. [Retrieved: 22/02/2012]. 
CSIERNIK, R. 2004. A review of EAP evaluation in the 1990s. Employee Assistance Quarterly, 19(4):21-37.

DE VOS, A.S., STRYDOM, H., FOUCHÉ, C.B. \& DELPORT, C.S.L. 2011. Research at grassroots - for the social sciences and human services professions $\left(4^{\text {rd }} \mathrm{ed}\right)$. Pretoria: Van Schaik Publishers.

MASI, D.A. 1994. Evaluating your employee assistance and managed behavioural care programme $\left(1^{\text {st }} \mathrm{ed}\right)$. Washington: Performance Resource Press Inc.

NISSLY, J.A. \& MENNEN, F.E. 2002. Intervening in response to job stress: highlights and recommendations from the research literature. Employee Assistance Quarterly, 17(4):15-30.

Press release by Bytes Technology Group \& Predictive Communications (Pty) Ltd. 2011. Employee Absenteeism costs SA up to R20bn a year. [Online] Available: http://www.bytessi.co.za/news/news_archive_article16.html [Retrieved:15/3/2012]

SEIDI, W. 2010. The evidence-based practice continuum in employee assistance: describing our profession's knowledge base and proving its value will help establish employee assistance as a unique profession. The Journal of Employee Assistance, 40(2):20-23.

SELVIK, R., STEPHENSON, D., PLAZA, C. \& SUDGEN, B. 2004. EAP impact on work, relationship and health outcomes. The Journal for Employee Assistance, 34(2):18-22.

SHARAR, D. \& LENNOX, R. 2009. A New Measure of EAP Success. A workplace outcome-based survey model provides validation. [Online] Available: http:www. shrm.org/Publications/E-mailNewsletter/Pages/default.enspx.

STALIKAS, A. \& DE STEFANO, J. (1997) Client Process in short term dynamic psychotherapy. Counselling Psychology Quarterly, 10(1):2-10.

STEELE, P.D. 2002. The treatment gap. EAP Digest. Fall 2002.

STEWARD, W.F., RICCI, J.A., CHEE, E., STEVEN, R., HAHN, S.R. \& MORGANSTEIN, D. 2003. Cost of lost productive work time among US workers with depression. The Journal of the American Medical Association, 289(23):3135-3144.

SWEET, S. \& CASEY, J. (eds). 2010. Work and Family Encyclopedia. Chestnut Hill, MA: Sloan Work and Family Research Network. [Online] Available: http://wfnetwork. bc. edu/encyclopedia_entry.php?id=17296 \& area=All.

UECKERMANN, H. 2006. Jou griep kos SA ekonomie R20 miljard. Rapport Loopbane, 2 Junie.

Dr Anneline Keet, Department of Social Work, University of the Free State; Prof Lourie Terblanche, Department of Social Work and Criminology, University of Pretoria, Pretoria, South Africa. 